\title{
Shared Responsibility for Societal Problems The Role of Internal Activists in Reframing Corporate Responsibility
}

\author{
Girschik, Verena
}

Document Version

Accepted author manuscript

Published in:

Business \& Society

DOI:

$10.1177 / 0007650318789867$

Publication date:

2020

License

Unspecified

Citation for published version (APA):

Girschik, V. (2020). Shared Responsibility for Societal Problems: The Role of Internal Activists in Reframing Corporate Responsibility. Business \& Society, 59(1), 34-66. https://doi.org/10.1177/0007650318789867

Link to publication in CBS Research Portal

\section{General rights}

Copyright and moral rights for the publications made accessible in the public portal are retained by the authors and/or other copyright owners and it is a condition of accessing publications that users recognise and abide by the legal requirements associated with these rights.

Take down policy

If you believe that this document breaches copyright please contact us (research.lib@cbs.dk) providing details, and we will remove access to the work immediately and investigate your claim. 


\section{Shared Responsibility for Societal Problems: The Role of Internal Activists in Reframing Corporate Responsibility Verena Girschik}

Journal article (Accepted manuscript*)

\section{Please cite this article as:}

Girschik, V. (2018). Shared Responsibility for Societal Problems: The Role of Internal Activists in Reframing Corporate Responsibility. Business \& Society. D01: 10.1177/0007650318789867

\section{DOl: https://doi.org/10.1177/0007650318789867}

Copyright (C) The Author(s) २०18. Reprinted by permission of SAGE Publications.

* This version of the article has been accepted for publication and undergone full peer review but has not been through the copyediting, typesetting, pagination and proofreading process, which may lead to differences between this version and the publisher's final version AKA Version of Record.

Uploaded to CBS Research Portal: July २०19 


\title{
Shared Responsibility for Societal Problems:
}

\section{The Role of Internal Activists in Reframing Corporate Responsibility}

\author{
Verena Girschik \\ Copenhagen Business School \\ vg.msc@cbs.dk
}

This article addresses intra-organizational pressures for organizational transformation toward more responsible business practices by exploring the role of internal activists. Building on the interactive framing perspective, I ask how internal activists develop a framing of their company's responsibilities as they attempt to transform its business practices from the inside out. I explore this question in the context of a Danish pharmaceutical company's responsibilities regarding the rising diabetes problem. Grounded in an inductive, interpretive analysis, I show how internal activists developed a framing of the company's responsibility over time and eventually instigated new ways of thinking about and doing business in their organization. I theorize the constitutive processes that strengthened frame alignment and allowed the internal activists to shape business practices. My study contributes to the literature on CSR communication by explaining how intra-organizational processes of meaning-making may constitute more responsible business practices and by explicating the distinct role of internal activists as agents of organizational transformation.

\section{Keywords}

Corporate responsibility; corporate responsibility communication; frame alignment; interactive framing; internal activists 


\section{Author}

Verena Girschik is Assistant Professor of CSR, Communication and Organization at Copenhagen Business School. Her research explores the intra- and inter-organizational dynamics of corporate responsibility in the context of complex societal problems. 
Companies face ever increasing pressures to assume responsibility for addressing contemporary societal problems like health crises or environmental degradation (Matten \& Crane, 2005; Scherer, Rasche, Palazzo, \& Spicer, 2016). External pressures, such as activist strikes (McDonnell, King, \& Soule, 2015) or contentious politics (Reinecke \& Ansari, 2016), may prompt the re-negotiation of corporate responsibility: For what problems ought companies to assume responsibility? And how ought they to contribute to solutions? Realizing that the outcomes of such negotiations may establish, maintain, or threaten their legitimacy — their license to operate (Joutsenvirta \& Vaara, 2015)—many companies publicly talk about responsibilities that stretch far beyond business-as-usual. Such CSR talk maysometimes_-instigate more responsible business practices (Christensen, Morsing, \& Thyssen, 2013; Haack, Schoeneborn, \& Wickert, 2012; Hamilton \& Gioia, 2009). Nonetheless, there is a risk that business continues as usual behind the scenes (Boxenbaum \& Jonsson, 2008; Bromley \& Powell, 2012; Meyer \& Rowan, 1977). Such "window-dressing” is problematic because a company may gain or maintain legitimacy by claiming that it assumes responsibility for addressing a problem, while its contributions-if any-remain marginal. Even worse, window-dressing may divert attention from corporate irresponsibility and malpractice.

Notwithstanding the potential of external pressures to instigate corporate responsibilization, an emerging stream of literature points at micro-level intra-organizational dynamics as key drivers of genuine transformation toward more responsible business practices (Aguinis \& Glavas, 2012). This literature calls for attention to the inner workings of organizations in the context of corporate responsibility (Meyer \& Höllerer, 2014), and has begun to explore "how CSR is developed, articulated and practiced" (Costas \& Kärreman, 2013, p. 395). An important role in intra-organizational dynamics may be played by organizational members who emerge as protagonists of corporate responsibility — as internal 
activists. Internal activists believe in and identify with corporate responsibility and may mobilize others in an endeavor to promote different ways of thinking about and doing business. They may thereby build bottom-up pressure for transformation internally and prevent or overcome window-dressing. Despite their importance, we still only have an elemental understanding of how internal activists author or shape responsibility talk as they attempt to transform their company's business practices from the inside out (Wickert \& De Bakker, 2016).

Addressing this lacuna, I adopt an interactive framing perspective (Cornelissen, Durand, Fiss, Lammers, \& Vaara, 2015; Gray, Purdy, \& Ansari, 2015). Framing plays a major role in intra-organizational processes, for instance in how internal activists frame social issues as they attempt to sell them to top management (Alt \& Craig, 2016; Wickert \& De Bakker, 2016). However, most studies adopt a sender-centered view of communication as rhetorical strategy and thereby risk the reduction of framing to self-presentation. Instead, the interactive framing perspective draws attention to how actors construct shared understandings in struggles over meaning with those whose support they aim to secure (Benford \& Snow, 2000; Snow, Rochford, Worden, \& Benford, 1986). Building on this view of framing as meaning negotiation, I am interested in the efforts of internal activists to achieve a shared understanding of what corporate responsibility means. Hence, I ask: How do internal activists develop a framing of their company's responsibilities as they attempt to inspire new ways of thinking about and doing business?

I explore this question in the context of a Danish pharmaceutical company's responsibilities as to diabetes, a chronic disease recognized as global epidemic with the potential to cause a worldwide healthcare crisis (e.g., World Health Organization, 2014, 2017). I traced the framing work of internal activists through an inductive, interpretive analysis of how they developed a framing of the company's responsibility over time as they 
conducted a series of country reports, so-called Blueprints for Change, and eventually instigated new ways of thinking about and doing business in their organization. Grounded in the empirical analysis, I present a model of the frame alignment process and theorize the constitutive processes that drove the development of the framing. By offering an empiricallygrounded account of how internal activists authored and shaped CSR communication, this article contributes to our understanding of the intra-organizational processes of meaningmaking that may transform companies toward more responsible business practices.

\section{The Interactive Framing of Responsibility}

Framing pertains to the interactive construction of interpretation schemes in which actors negotiate a common understanding of experiences (Benford \& Snow, 2000; Snow et al., 1986). Through framing, actors define problems, propose solutions and motivate action. These three framing tasks are a cornerstone in the negotiation of responsibilities, especially in the context of complex societal problems that defy unambiguous definition (Reinecke \& Ansari, 2016). If an emerging framing succeeds in mobilizing broad-based support, it may evolve into a field frame, a relatively stable frame that - while still subject to modificationattains "the durability and stickiness akin to an institutional logic" (Lounsbury, Ventresca, \& Hirsch, 2003, p. 72). A company's framing of its responsibilities may thus carry significance beyond the organization, for example as it formulates a vision for far-reaching change and inspires news ways of thinking and doing (Werner \& Cornelissen, 2014). Indeed, framing processes have been shown to drive the emergence of new fields (Granqvist \& Laurila, 2011),

industries (Lounsbury et al., 2003), and market categories (Khaire \& Wadhwani, 2010; Weber, Heinze, \& DeSoucey, 2008).

Most contributions, however, have viewed framing merely as a rhetorical strategy used instrumentally by actors to advance their own stakes (Cornelissen et al., 2015). 
For example, several studies have focused on identifying actors' frames and how they use them in framing contests (e.g., Kaplan, 2008; Lefsrud \& Meyer, 2012). This perspective considers other actors as passive-as the voiceless targets of strategic efforts-thus suggesting asymmetry between senders and receivers. Because of this sender-centered view of communication, the rhetorical perspective risks the reduction of framing to selfpresentation and influence over others (Cornelissen et al., 2015). As it locates meaning "between the ears" rather than "between the noses" of people (Dewulf et al., 2009, p. 162), it overlooks how frames are interactively constructed through ongoing and sometimes subtle negotiations over meaning. This is problematic because to explain how framing processes may produce action requires that we understand how actors construct framings in negotiation with others as they attempt to achieve frame alignment with those whose support they aim to secure (Dewulf et al., 2009; Gray et al., 2015).

Frame alignment involves micro-political struggles over meaning in which actors attempt to match their understandings and create fit (Benford \& Snow, 2000; Snow et al., 1986). Whenever actors communicate with rather than to others, they may encounter conflicting interpretations, or mismatches of understandings. Attempts to resolve such conflicts and achieve a shared understanding may prompt them to engage in interpretive work and to revise their own understandings. Such adjustments may then lead to shifts in a framing, for example when actors reconsider their definition of a problem or their proposed solution. Accordingly, any observed unproblematic alignment or shift in a framing may indicate repaired misalignment. Especially when a problem is complex and responsibility attribution is ambiguous, however, we may observe multiple interpretive shifts before a stable framing emerges at the field level (Reinecke \& Ansari, 2016).

While achieving frame alignment is crucial for mobilizing participation and action, we know little about why actors revise their understandings (Cornelissen et al., 2015; 
Werner \& Cornelissen, 2014). Shifts in meaning may occur from both strategic and uncalculated efforts (Gray et al., 2015), but not all instances of communication and interaction shape or transform meaning. Rather than taking the transformative effects of communication for granted, we therefore need to ask what processes constitute new understandings and behaviors (Alvesson \& Kärreman, 2011; Brummans, Cooren, Robichaud, \& Taylor, 2014; Cooren, Kuhn, Cornelissen, \& Clark, 2011). The problematizing of transformative effects draws attention to the conditions under which communication brings about new ways of thinking and acting. To explain when and how CSR communication may bring about organizational transformation, we must hence understand the constitutive processes that enable meaning-making and the construction of a strongly aligned framing of a company's responsibilities.

\section{Empirical Approach and Methods}

To shed light on the processes that constitute frame alignment and drive the development of an appealing framing of a company's responsibilities, this article focuses on how a team of internal activists produced a series of country reports - so-called Blueprints for Change - in which they present the Danish pharmaceutical company Novo Nordisk's activities aimed at improving diabetes care.

\section{Research Context}

Novo Nordisk is a Danish-headquartered pharmaceutical company focused on the development, production and marketing of insulin used for treating diabetes, and has achieved a leading position in the industry, holding a global share of $26 \%$ in the insulin market in 2014. In addition, the company is considered a corporate responsibility leader, 
having risen to second place in the Access for Medicine Index in 2014 and scoring consistently high in the Corporate Knights index of the Global 100 most sustainable corporations and the Dow Jones Sustainability Index. Novo Nordisk's dual success lies at least partly in its long history of stakeholder engagement rooted in the Scandinavian tradition of cooperative stakeholder relations which rejects a narrowly economic view of the firm (Strand \& Freeman, 2015; Strand, Freeman, \& Hockerts, 2015). Indeed, the Triple Bottom Line has been part of Novo Nordisk's Articles of Association, the company's bylaws, since 2004, and is highlighted in the company's identity statement, the so-called Novo Nordisk Way. Because, so they argue, it reflects the way they do business, Novo Nordisk does not issue a sustainability report, but instead has been advocating integrative reporting. Like the integrated annual report, the Blueprint for Change reports present the company's activities in an integrated fashion. Yet each Blueprint for Change report zooms in on a single country and therefore allows for a great level of detail.

The company operates in 75 countries, including many developing countries and emerging markets. The Blueprint case countries are selected based on strategic considerations and, by 2017, seven countries had been covered, including China, the US, Bangladesh, Indonesia, India, Turkey, Russia, Algeria, and Japan. The reports were constructed by a team within the Global Stakeholder Engagement group, to which I will henceforth refer as "Blueprint team." I consider the Blueprint team internal activists because I consistently found that the team questioned and problematized dominant business objectives and that they were driven by the ideological motive to augment the company's responsibilities in addressing societal problems. In the making of the reports, the Blueprint team collaborated with Novo Nordisk's local subsidiaries and engaged with local stakeholders. Moreover, all reports had to be approved internally by Corporate Communications, the legal department, Corporate Branding and, if applicable, regional 
headquarters. Finally, the Blueprint reports were presented to an internal audience before publication on the corporate website. During the construction of the reports, the team hence interacted with a variety of internal and external stakeholders, and the reports reflect settlements of their negotiations_ — albeit temporary and malleable.

The Blueprint for Change series of country reports offers a rare opportunity to explore how internal activists developed a framing of their company's responsibilities. First, any temporary settlements in such processes often remain implicit and hence difficult to study. The Blueprint reports, however, make the settlements explicit and thereby facilitate analysis of how and when the framing changed over time. Being able to pinpoint these changes enables a more precise linking of changes in the framing to the internal activists' interactions with other actors and protects from distortions that might arise from retrospection. Second, Novo Nordisk's long history of stakeholder engagement entails a mature practice of aligning with stakeholders, and the internal activists built on this practice as they skillfully mobilized both external and internal stakeholders. The case hence offers an exceptional opportunity to study a process in which internal activists developed the framing of the company's responsibilities through interaction with a variety of other actors, achieved a high degree of alignment, and eventually began to transform business practices in their organization.

\section{Data Sources}

To trace the development of the framing over time, I conducted an in-depth analysis on nine country reports in the Blueprint for Change series. The reports are publicly available on Novo Nordisk's corporate website. The first Blueprint report was issued in 2011, and the latest report included here was issued in 2017. The length of the reports varies from 16 to 28 pages, 
and each report has a distinct theme. Table 1 provides a timeline of the reports, and displays the codes used to refer to the reports in the remainder of this article.

Table 1 about here

To tap into the context and interactions with other actors that drove the development of the framing and to cover the entire series of reports, I complemented the reports with several other data sources. First, I build on 14 days of participant observation during which I followed the Blueprint team's work on the Blueprint for Indonesia between August 2012 and March 2013, which also included three meetings of the team with the general and financial managers of Novo Nordisk's Indonesian subsidiary. Additionally, I accessed internal emails on the publication of the Blueprint in Indonesia and its effects in Spring 2013, and an internal methodology document: a guidebook of 20 pages that outlines how the Blueprint reports should be constructed, and which was developed by the Blueprint team in 2012 while constructing the Blueprint on Indonesia. While these data were collected during the construction of the Blueprint for Indonesia, they also allow me to access how the team constructed previous reports, particularly the Blueprint for Bangladesh, as the team told the stories of previous reports and juxtaposed cases. In addition, I build on five meetings held in 2014 and early 2015, in which the team and I discussed their framing efforts. The last of those meetings took place after preliminary analysis of the reports, and centered specifically on the Blueprint team's reflections on the entire series of Blueprint reports. I took detailed research notes on the team's efforts and considerations throughout, and all meetings were tape-recorded and transcribed verbatim. Finally, I held two reflection meetings with the 
team's leader in early 2017 , during which he shared recent developments and talked about the latest Blueprint reports. I afterwards received the communication plan for Japan as well as detailed explanations from a second team member. Public documents, including Novo Nordisk's publicly available Access to Health Strategy as well as information on access to health and efforts to change diabetes care provided on the corporate website served as background information.

\section{Data Analysis}

Inspired by the grounded theory approach (Charmaz, 2006; Corbin \& Strauss, 2008), I worked inductively with the aim to build process theory (Langley, 1999; Mohr, 1982). In line with the interactive framing perspective, I analyzed both the framings espoused in the reports and the construction processes. To begin with, I conducted an in-case preliminary analysis of each Blueprint report, summarizing the structure and main argument on around four pages per case. Drawing on my data on the company's challenges in the case countries and of the process in which the reports were constructed, I included contextual information in the summaries. This preliminary analysis allowed me to reduce the complexity of the data by defining four phases as temporal brackets (Langley, 1999). Specifically, I defined that a new phase started when the framing of Novo Nordisk's responsibilities or the construction process changed. The first phase includes the Blueprints for China and the United States; the second phase includes the Blueprints for Bangladesh and Indonesia; the third phase includes the Blueprints for India, Turkey, and Russia; and the fourth phase includes the Blueprints for Algeria and Japan.

For all phases, I traced the development of the framing and the interactions of the Blueprint team with others inside and outside the company. In my analysis of the reports, I first generated first-order codes that described how the framing fulfilled the three framing 
tasks described by Benford and Snow (2000), thereby paying particular attention to how the reports articulate the problem and attribute responsibility. Using the framing tasks as theoretical, second-order concepts, I compared coded passages in the reports and identified shifts in the framing over time. To understand the constitutive processes that prompted the shifts in the framing, I coded all other data for interaction. Specifically, I coded all passages that concerned direct interactions with other actors, personally or written, as well as passages in which the Blueprint team mentioned of other actors. I found that the latter passages often described how the team had experienced interactions or what they believed were important considerations, thus offering insights into the team's understanding of other actors. Because relevant stakeholders included both external actors and internal managers, I used internal and external alignment as theoretical dimensions to group the coded interactions. Using time as main organizing principle, I then connected the two disparate parts of my analysis and constructed an analytical narrative.

Connecting the shifts in the framing and the interactions that preceded them as well as accounts thereof enabled me to define and label the constitutive processes. For example, in the second phase, the team met and talked to stakeholders that were not only experts but also key opinion leaders in the field of diabetes care, and who had already been working on improving diabetes care through their own projects. Interactions with these stakeholders led the Blueprint team to recognize stakeholders' capacities, and thereby prompted a shift in their understanding from stakeholders as passive recipients in need of the company's assistance to potential partners. I hence attributed the shift in the framing to the constitutive process of recognizing stakeholders' capacities. Table 2 presents the frame shifts, constitutive processes, and illustrative quotes. 
Table 2 about here

\section{Findings}

How did Novo Nordisk's Blueprint team develop a framing of the company's responsibilities? The Blueprint team began their work by producing what may be considered traditional PR talk. Over time, however, the team increasingly interacted with stakeholders, which changed how they understood and talked about Novo Nordisk's responsibilities. As they developed what I refer to as "shared responsibility framing", the team gained access to strategizing processes in several of the company's subsidiaries and began to shape managers' decision making principles and business practices throughout the organization. In what follows, I detail the shifts in the Blueprint team's framing of their company's responsibilities and show the interactions that drove the development and increasing alignment of the framing over time.

\section{Phase 1: Measuring the Impact of Responsibility Investments}

When the Blueprint team started their work, they had received the explicit mandate by top management to offer an assessment of the company's CSR investments by measuring impact in terms of economic, social, and environmental outcomes. The reports were considered "investor products", or traditional PR talk, meant to transmit information about the company's activities. In the first phase, the team used what I refer to as "traditional corporate responsibility" framing. While these formulations will appear familiar, I begin my analysis by 
detailing this framing to offer an understanding of the idiosyncrasies of the Novo Nordisk case and to establish the baseline for ensuing shifts.

Early diagnostic formulation: a complex societal problem. The wicked problem to which Novo Nordisk responds - and which is described in all reports-is the diabetes epidemic. The Blueprint on China begins by devoting a page to establishing the growing burden posed by the disease for individuals and society, drawing on publicly available data to show the increasing prevalence and displaying projections in a graph. The data are invigorated by quoting the Chinese Health Minister: "Chronic diseases such as diabetes and hypertension are becoming public health challenges" ( $\mathrm{CN}$, p. 3). Further enforcing a sense of urgency, the Blueprint warns: "Increasing childhood obesity in China is to diabetes and chronic diseases what melting glaciers are to climate change: a warning signal of times to come" (CN, p. 3). Similarly, the Blueprint on the US advises that "the diabetes epidemic is growing at an alarming rate" (US, p. 14), and a graph illustrates the projection that the total annual direct medical and indirect societal costs of diabetes to 215 billion US dollars over the next 15 years. The growing costs—in addition to human suffering — suggest an urgent need for intervention. In addition to societal implications, increasing diabetes prevalence has clear business implications: although not articulated explicitly in the report, for Novo Nordisk, since the company's main business rests on insulin, growing diabetes prevalence is an indicator of market growth.

In addition to creating a motivation and urgency for intervention, the Blueprint on the US elaborates on the nature of the problem. Diabetes is presented as a complex and multifaceted challenge. The Blueprint specifies five categories of drivers: individual, healthcare system, social, government, and public awareness. A figure lists specific challenges in each category resulting in a comprehensive yet diverse presentation, including, for instance, individuals' genetic disposition and history cardiovascular disease, healthcare 
practitioners' education, governmental food supply policies and media coverage. As presented, the drivers of the problem are diverse and defy the narrow definition of a single root cause. The early formulation of the framing does not allow the formulation of specific intervention, but instead suggests a broad approach: "Diabetes trends present a complex challenge that requires interventions on multiple fronts" (US, p. 6).

Early prognostic formulation: corporate responsibility investments. Assessing the value created for business and society, the Blueprint team formulated Novo Nordisk's intervention in China as a "holistic strategy that went beyond business as usual—provision of new innovative treatments and services - by also focusing on physician training, patient education, strengthening the healthcare system, public awareness, local production and R\&D” (CN, p. 4). The report focuses on assessing the effects of Novo Nordisk's intervention, and for that purpose leverages the company's Triple Bottom Line approach by examining business, economic, social and environmental value created by specifying value drivers, such as profit, employment, and access to health, that afford operationalization for quantitative measurement, such as market share, number of jobs created, number of life-years saved and $\mathrm{CO}^{2}$ reduction. By providing quantitative evidence on the efficacy of corporate responsibility investments, the Blueprint on China demonstrates outcomes in terms of value created on the distinct dimensions.

While maintaining focus on assessing the value created through sustainability investments, the Blueprint team introduced the notion of shared value creation in their report on the US. As the report defines shared value, it is "about realizing synergies between business and society" (US, p. 26). The introduction of the shared value idea into the Blueprint draws attention to the potential for a business strategy that integrates business and societal objectives. Still, the intervention is described as a stakeholder-focused business strategy, defined as business solutions "addressing patient, societal, and stakeholder needs" (US, p. 3). 
Importantly, in this traditional responsibility framing, stakeholders feature as the targets of the proposed intervention-as those who may benefit from the company's corporate responsibility investments.

\section{Phase 2: External Alignment}

The Blueprint reports for China and the US were received well by external stakeholders. In particular, the report on China caught Michael Porter's attention and has been used as a showcase for Shared Value Creation (Porter, Hills, Pfitzer, Patscheke, \& Hawkins, 2011). The Blueprint team was therefore asked to construct additional reports for countries that management considered successful cases. As the team confronted the local contexts of Bangladesh and Indonesia, however, they observed alternative ways of doing business that would challenge their understanding of the company's responsibilities. In interaction with local managers and stakeholders, they theorized their observations and developed a new framing.

Shift 1a: From root causes to barriers to care. When starting on the report for Bangladesh, the team was faced with a different local situation. In most developing countries healthcare systems are not equipped to deal with diabetes and patients are often neither diagnosed nor treated until they experience serious or even lethal complications. Because Novo Nordisk's business is diabetes treatment, lack of diagnosis and treatment implies that there is no market for its products. In Bangladesh, however, the team discovered that the local subsidiary had established collaboration with local stakeholders to improve diabetes careand had thereby successfully built the market. Later, the general manager who had led the company's success in Bangladesh was using a similar approach in Indonesia. The confrontation with developing country contexts characterized by inappropriate provisions of 
diabetes care made the team realize that a well-functioning healthcare system constituted paramount infrastructure not only for public health but also for the company's market.

The remarkable success in Bangladesh and the challenges faced in Indonesia led the Blueprint team to search for an understanding of how the company could contribute to improving diabetes care. It had soon become clear that the problems with care required engagement beyond traditional strategies, such as lowering prices. In Bangladesh, a least developed country, the company sold generic products at a discount, yet the Blueprint team understood that pricing did not make a difference before a combination of other initiatives were taken:

In Bangladesh, lowering the price did not change the volume. Distribution was key. [The General Manager] got threatened by a distributor because he lost his life work. But the change led to $9 \%$ change annually. (Blueprint team member, Sep 12)

Yet distribution was only one aspect of a more complicated problem, and the team in fact constructed a long list of interdependent barriers to improved care. In addition to learning about the subsidiary's actions through the local staffs' accounts, the Blueprint team traveled to both Bangladesh and Indonesia, where they visited local hospitals and conducted interviews with policy makers, doctors, and patients. The list of barriers they confronted included, but was not limited to, the absence or unreliability of refrigerators in pharmacies and patients' homes so that insulin could not be safely stored, doctors who did not recognize the symptoms of diabetes, and patients who believed that insulin would cause heart attacks and kidney failures. The team documented their experiences by recording conversations and taking pictures, to which they would often return while constructing the report. While the team immediately realized that such complex and multifaceted problems with diabetes care 
required action on several fronts, their diagnosis lacked the specificity that would allow them to understand why the interventions of the subsidiary in Bangladesh had been successful.

This lack of understanding prompted the team to develop tools for analysis. In collaboration with external consultants, the team introduced the so-called comprehensive barriers model, or 4AQ model. First presented in the Blueprint on Bangladesh, the model defines five dimensions that may harbor barriers to diabetes care: accessibility, availability, affordability, awareness, and quality of care. In the Blueprint on Bangladesh, the model is presented as developed in collaboration with local stakeholders and based on the corporate access to health strategy. Yet the model's significance is strengthened in the Blueprint on Indonesia through reference to the global discourse on access to health:

Our approach to healthcare access is rooted in the Universal Declaration of Human Rights, which defines right to health as essential for an adequate standard of living. Four key elements shape the right to health: availability, accessibility, affordability and quality. In addition, the World Health Organization has identified awareness of diabetes as a critical barrier in developing countries. Together, these five barriers form a framework for identifying diabetes care issues in Indonesia. (ID, p. 4)

The introduction of the 4AQ model shifted attention from the root causes of the problem toward the interdependent, immediate barriers that would need to be addressed to achieve a non-contested, desired state: a well-functioning system of diabetes care in which patients receive appropriate care and medicines.

Shift 1b: From stakeholders in need to stakeholders as partners. In the first phase, the Blueprint reports had been centered on assessing how the company's corporate responsibility investments served stakeholders needs. In Bangladesh, however, the company had established a partnership with a local NGO, which the Blueprint team encountered during 
their visit, and which they considered crucial to Novo Nordisk's success. A member of the Blueprint team re-tells the story of how the collaboration developed.

Prof. Khan came to us and said: can we do education together? And we said yes, of course, we can do education together. But we cannot pay for it always. And Prof. Khan also thinks that if we are paying for it always, then we can't have money for other project. So he said no, let me put up a revenue model, where I get physicians to come, so you help me build the system, and then physicians are coming to him, and paying for their education. So it's now a selfsustaining system. And that can be scaled up. Because he is now earning money for physicians from outside to come and be educated. And they get a certificate, that is approved by the government, and then they leave again. So they are paying for their education. What we do, we pay for upgrading. Making sure that the knowledge, that they use, is always top notch and the best. But the fact is, this is a very sustainable model. And I think that this is very, very clever work from Prof. Khan, what he has done.

In addition to setting up the education system for general practitioners, the key stakeholder championed the diabetes agenda using his close personal relationship with key government officials. The discovery of the subsidiary's collaboration with local stakeholders, stakeholders' capacities, and the remarkable results of the collaborative approach prompted a rethink of the role of stakeholders as mere recipients of the company's investments to also considering them as potential partners with significant capacities.

Attempting to capture how the collaboration worked, the team constructed the Blueprint on Bangladesh as "an analysis of how we worked with Prof. Khan” (Blueprint team member, Sep 12). The Blueprint presents a "flow model" of products and goods that stakeholders exchange, displaying what partners offer and gain in return. For example, Novo 
Nordisk offered financial resources and insulin to the local NGO and receives reputation benefits and profits in return. The flow model remained relatively simple in the Blueprint for Bangladesh because there was only one key partner. In Indonesia, the company faced multiple stakeholders, including a stronger government, professional and patient organizations, and insurance companies. Reflecting these challenges, the Blueprint for Indonesia presents a more complicated partnership model with several partners and an even more pronounced allocation of different responsibilities that reflects the team's as well as stakeholders' own understandings of their capacities: For example, the government was responsible for policymaking and coordination, the professional organization was responsible for access to care and for improving healthcare practitioners' capacities, the patient organization wass responsible for improving awareness (ID, p. 8). Acknowledging other stakeholders' capacities shifted the framing from stakeholders as those depending on the company's assistance toward stakeholders as partners, thus acknowledging the company's dependency: "No one can tackle the diabetes epidemic alone-it requires partners to work together" (BD, p. 21). Or, as expressed in the Blueprint for Indonesia: "Novo Nordisk is committed to changing diabetes in Indonesia, but we cannot do it alone.” (ID, p. 8).

Shift 1c: From corporate responsibility to remedial responsibility. In Bangladesh, the Blueprint team had faced a well-established and well-functioning partnership. In Indonesia, in contrast, establishing partnerships with local stakeholder was proving more difficult for the local subsidiary. Indonesia is an emerging market with a growing middle class, and Novo was not selling generic medicine at a discount, like they did in Bangladesh. Stakeholders-particularly the professional association of endocrinologist, key opinion leaders and experts in the field-contested Novo Nordisk's market strategy. Aware of the challenge in their preparation for field work in Indonesia, the Blueprint team acknowledged: "Trust and credibility in society are a main barrier for Novo Nordisk" 
(Blueprint team member, Sep 12). In addition to this generally more critical sentiment among stakeholders, competitive pressure from other companies posed a new challenge. In a meeting with the Blueprint team (Sep 12), the financial manager of the Indonesian subsidiary elaborated: "Stakeholders are very money-driven. With the endocrinologists, the discussion goes like this: We have project that we want to do, if you don't fund it I will ask Sanofi. They know that the pharma industry has money, and they use it. Novo has very low bargaining power." Because of these challenges, emerging relations and collaboration had remained fragile and vulnerable to stakeholders' commitment.

When initiating the construction of the Blueprint, the Blueprint team explicitly agreed with the general manager of the Indonesian subsidiary that the purpose was not to retrospectively report on what had been established, but rather to use stakeholder engagement to strengthen the company's reputation and stakeholders' commitment. To this end, the strategy for the Blueprint, they agreed, should be to first talk to several key opinion leaders separately, then construct the report, and finally bring them together. This strategy was chosen "to avoid trouble" (General manager, Aug 12): to avoid debates and conflicts. During their field trip, the Blueprint team got acquainted with stakeholders' understanding of their own responsibilities and interests, and they applied their gained understanding to formulate calls for action. For instance, it encouraged the government to pursue what it had set out to achieve: "The government must set the direction, following through on implementation of the NDP (National Diabetes Plan)" (ID, p. 8).

Overall, the Blueprint for Indonesia presents a proposal for collective intervention: "Facing this challenge compels stakeholders to align their vision in a way that leads to better awareness and improves access, affordability and quality of care." (ID, p. 1). While the responsibilities of others are clearly formulated, however, the company's own responsibilities remained under-defined. All stakeholders, according to the model, should 
contribute in ways that serve their interests and that leverage their distinctive capacities. The definition of the company's responsibilities, however, are defined merely as complementary to those of others. For example, while the company has top notch expertise, the Blueprint for Indonesia positions the local professional organization as experts and emphasizes that the company must support others in their endeavors: "[T]his kind of interdependent web requires that we understand the strengths each entity brings to the value chain and how we can support their efforts." (BD, p. 21). The company's capacities and responsibilities are malleable, as a Blueprint team member reflected: "These people are part of our journey. And we need to remember that we are what they say we are" (Blueprint team member, Feb 15).

In Indonesia, the Blueprint was "launched" in an official celebration during which key stakeholder were present and endorsed the report. Because the Blueprint in Indonesia so successfully increased the commitment of key stakeholders and inspired collective action, it set in motion the idea that such communication could be applied strategically to other markets:

I think that your combination of a blueprint (and the stakeholder engagement process that it entails), HCP training, patient education and a policy roundtable is a best practice, and my team will reach out to see how we "package" this process/concept for other affiliates [subsidiaries] to use. (Vice president of global public affairs and stakeholder management, internal communication, Mar 13).

The success of the Blueprint in Indonesia incited the third phase in the team's work, in which they set out to promote their new understanding throughout the company.

\section{Phase 3: Internal Alignment}


After the success of the Blueprint in Indonesia, many other local general managers asked the team to construct a report on their local activities:

In the beginning, it was hard to convince subsidiaries to participate. They were very critical. But now, it's no problem at all. There are many who want a Blueprint. We can't even do them all. (Blueprint team member, Sep 14)

Yet despite the success of the Blueprint in Indonesia and increasing demand for their work, the Blueprint team faced re-negotiations of their budgets and resources, which prompted them to reflect:

What are actually our core competences in the Blueprint for change team? What is it that we are so good at that we should not jeopardize when trying to be more efficient? ... The field work, the market research, this is the time we are being squeezed most on. However, somehow I see it as the strongest thing that we actually do. And if we don't have that, then what is it that we have?

The team interpreted these re-negotiations as threats to their position and their project. Instead of abandoning their project of promoting their new understanding throughout the organization, however, the team increased attention to internal political processes and started to target managers.

Shift 2a: From most pressing issues to issues with greatest potential impact. Indonesia was a market of strategic importance and enjoyed the benefits of corporate strategic investments. Already in the initiation of the Blueprint, subsidiary managers had emphasized repeatedly that "big money" was channeled to the subsidiary. For spreading the new framing throughout the organization, the Blueprint team was aware that it had to propose a "package" that would work in countries not benefiting from large investments. A Blueprint team member explained: "The way decisions navigate is through top management looking at where they see growth potential, and where they can realize that potential with the least 
effort." In order to appeal to managers, the team therefore made more explicit the business case by the impact of investments on market building and the company's share. To illustrate, another Blueprint team member explains:

So it's not only about new patients, but also new patients on our insulin. How many will ever get treatment, how many will get insulin, and how many will get our insulin. And all these steps imply the question: is screening a cost-effective way to get new patients? Maybe you shouldn't invest in screening, maybe you should invest in that everybody who is already diagnosed today will get treatment, maybe your money will pay a bigger role there.

To promote their framing inside the company and inspire the adoption of new business models in other subsidiaries, the team hence attempted to generate an advanced understanding of the business case, grounded in the analysis of their previous Blueprint cases.

In the Blueprint for Indonesia, the 4AQ barriers model had been amplified with the issues collected from stakeholders - 63 issues in total - and it presented a complex issue map that highlighted interdependencies, thereby offering the most comprehensive analysis of barriers to care. The analysis highlighted the "issues most acutely in need of attention" (ID, p. 7), which are addressed by the subsequently presented initiatives. In the case of Indonesia, the team had matched the most pressing issues with initiatives that were in progress. Attempting to make a more compelling case for investments, the team reduced the complexity in the diagnostic formulation by using the 4AQ model to specify and target interventions. In the Blueprint on India, the methods section states: "We use the comprehensive barriers model to guide our understanding of what the most acute needs are and which issues, if addressed, could create most value for people with diabetes and for all other stakeholders" (IN, p. 18). Further targeting the diagnosis in the Blueprints on Turkey 
and Russia, the 4AQ model is used to answer the question: "Where can we have the biggest positive impact?" For example, the Blueprint on Turkey presents (p. 7):

In the course of our research, awareness and affordability did not turn out to be areas where we could have the most impact, in part because of systemic factors. For instance, when there is universal healthcare, affordability becomes less of an issue. However, the elements in the framework are interlinked and many of our highlighted activities therefore affect these two elements in an indirect manner.

By emphasizing impact rather than issues considered in need of attention, the Blueprint team's framing aimed to tap into managers' common practice of prioritization, and to "offer a concrete value proposition" (Blueprint team member, May 15).

Shift $2 b$ : From remedial responsibility to shared responsibility. In addition to offering a stronger business case, however, the team realized that it had to offer a concrete and more practicable proposal. One recurring theme in their conversations was that-even though many local general managers were intrigued by the new understanding that the team was promoting, they had difficulty finding ways to apply it to their own activities. Reflecting this challenge of impracticability, the Blueprints team, based on their analysis and interaction with both managers and external stakeholders, attempted to offer more concrete proposals. Specifically, the Blueprint on India centers on the potential of public-private partnerships: "The public-private partnership approach offers a foundation for sustainable and large-scale ventures. It is how we help to create shared value in India" (IN, p. 2). Explicitly linking diagnosis and prognosis to a call for action, the Blueprint invites specific stakeholders: "Novo Nordisk wants to engage with state governments to break down the barriers to care for people with diabetes" (IN, p. 16). In addition, by reference to the company's identity statement - the Novo Nordisk Way—the Blueprints further specify envisioned responsibilities: "Our key 
contribution is to discover and develop innovative biological medicines and make them accessible to patients throughout the world" (TR, p. 8; RU, p. 8). Applied to the Turkish context, the Blueprint formulated the envisioned engagement as follows: "We actively seek partnerships that build healthcare professionals' skills, share scientific advancements with policy-makers and provide innovative products to patients.” (TR, p. 8). To this end, the Blueprint calls: "We invite both public and private organisations to join us in taking actions to implement sustainable solutions and work with us in our ambition to innovate diabetes care in Turkey" (TR, p. 20). Similarly, the Blueprint on Russia delimits investment in R\&D, local manufacturing and capacity building as three ways in which Novo Nordisk, in collaboration with partners, can make the most impact (RU, p. 20). As illustrated, the Blueprint reports specify courses of action for each country.

More generally, by more narrowly defining the company's responsibilities, the team attempted to define responsibilities that managers would be willing and able to implement. Solidifying the company's responsibility around the company's core competences contributes to the business case and defies expectations of investments beyond the company's direct interests. The narrower definition of the company's responsibilities reflects a compromise that commits the company to specific responsibilities - and defies others: the framing emphasizes other stakeholders' responsibilities, positing collaboration based on complementary capacities as a necessary condition for ameliorating societal problems. Shared responsibility hence delineates the company's responsibilities: rather than contributing with what is needed to address the problem, the framing suggests a more sophisticated and practicable understanding of what the company ought to do. As a Blueprint team member concluded: "Instead of creating value in a serendipitous way, we are now doing it in an intentional way." 


\section{Phase 4: Transforming Talk and Action}

By the end of the third phase, the team contently observed that local subsidiaries used the Blueprints to manage their public relations: The Blueprints had become "a tool for subsidiaries to use" (Blueprint team member, Jan 17). At the same time, however, they became concerned that subsidiary managers used them pragmatically to foster business interests. To illustrate, in Russia, the subsidiary thought it necessary to align closely with the government's political agenda. The Blueprint team was alerted when the subsidiary managers were eager to include a picture featuring the local general manager and a key political figure. During lengthy and fierce discussions with the subsidiary staff, the Blueprint team asserted that the inclusion of the picture would pose a threat to the integrity of the company. As a member of the Blueprint team explained to me: "We don't want to be associated with things such as homophobia. Imagine the consequences if people associate us with such a stance" (May 15). The incident alarmed the team that pragmatic attempts of stakeholder engagement by subsidiary managers could severely backfire.

In response, the team began to consider how it could change the Blueprint construction process to transform managers' ways of thinking. In Russia, they had trained executive managers in how to use the Blueprint and how to convey the message to external stakeholders; that is, how to talk the shared responsibility talk. In this fourth phase, the team expanded trainings by including local staff more strongly in the construction process, thereby turning the Blueprints into "local products" (Blueprint team member, Feb 2017). In Algeria, the Blueprint team aimed to co-construct potential courses of action, and in the processed discussed a great diversity of practices with local management, including, for example, the question: "how are the dogs that guard the factory treated?" (Blueprint team member, Feb 2017). The purpose of such discussions was to prompt local managers to revisit and revise their own understandings. Moreover, the team co-constructed an explicit stakeholder 
engagement strategy and trained managers and sales staff in how to leverage the insights from the Blueprint in their work.

Most recently, in Japan, the co-construction of the Blueprint extended over an entire year to accommodate the detail- and consensus-oriented mindset of Japanese managers. After completion, the Blueprint team designed an internal communication plan that aimed to "ensure a united voice and commitment to the Triple Bottom Line and to changing diabetes." The team again prioritized training executive management, but also conducted trainings of all middle managers "to further integrate insights from the Blueprint and TBL into their work" (Communication plan JP). What is more, they "conducted interviews with all the members of the executive team and created personal stories and testimonials from various areas that have been shared with all employees in the organization" (Blueprint team member, Feb 17). Aimed to "engage and motivate" all employees, this material has been communicated to all local staff, more than 3000 people.

\section{Toward a Model of Frame Alignment for Corporate Responsibility}

Theorizing my findings, I explain how internal activists may transform their company from the inside out by developing a framing of the company's responsibilities that achieves strong external and internal alignment. Figure 1 presents my model of the frame alignment process.

Figure 1 about here 


\section{External Alignment}

External alignment refers to constructing or changing a framing to generate fit with external stakeholders' understandings. Importantly, actors do not change the framing merely in response to external pressure (cf. Oliver, 1991; Pache \& Santos, 2010), but rather because interactions with external stakeholders prompt them to revise their own understanding. A strongly aligned understanding, in turn, enables actors to mobilize collective action. In the Novo Nordisk case presented here, the internal activists strengthened external alignment through three frame shifts: from root causes to barriers to achieving a desired state; from stakeholders in need of assistance to stakeholders as partners; and from the company's responsibility to invest in independent activities to the company's responsibility to invest as needed to support collective action. Three constitutive processes prompted the team to revise their understanding as expressed in these shifts: understanding a desired state; recognizing stakeholders' capacities; and acknowledging stakeholders' interests.

First, understanding a desired state entails learning how a company's objectives overlap with societal objectives. Because the definition of a desired state directs focus to barriers to achieving that state, or immediate causes, it enables the formulation of multiple, interdependent lines of action likely to produce prompt results. In contrast to root cause analysis, which renders a problem amenable to action by narrowing its scope (Reinecke \& Ansari, 2016), focusing on barriers to the desired state accommodates stakeholders' ideas and approaches by maintaining a broader scope that enables the flexible creation of various causal linkages. To illustrate, the framing of a well-functioning system of diabetes care as desired state accommodates both those who advocate preventive measures and those who aim to boost high-quality treatment, thus facilitating a collective intervention without the need for both groups to agree on all aspects. What is more, the implications of the projected change are diverse, in this case including market transformation and improved public health. When 
leveraged, overlapping objectives thus enable co-orientation and alignment of action, thereby facilitating collective action (Koschmann, Kuhn, \& Pfarrer, 2012). While, as in the case studied here, overlapping objectives may sometimes seem to present themselves, it is likely that, for most companies, this process requires internal activists to perform more interpretive work and may results in less intuitive objectives, such as the Danish brewery Carlsberg's 'responsible drinking' initiative (Christiansen, 2013).

Second, recognizing stakeholders' capacities entails understanding the local field of interdependent actors that have stakes in the problem and potential interventions, and draws attention to realized and potential dependencies. In the case presented here, recognizing stakeholders' capacities indeed involved confrontation with and thus a strong appreciation of the company's dependency—most saliently in terms of political will and legitimacy — and thereby prompted the shift in the framing that reflected this appreciation by proposing partnerships. Since any dependencies are constructed in the context of a given distribution of resources and institutionalized positions in the local field around the given problem (Hoffman, 1999; Oliver, 1991), an understanding of the local field may prompt a new understanding of the company's own capabilities in that field and motivate collective action. Gaining understandings of the field, however, requires not only that internal activists have achieved the organizational support that confers to them the mandate to interact with stakeholders, but also that they possess heightened sensitivity and social skills (Fligstein, 2001; Fligstein \& McAdam, 2012)

Third, acknowledging stakeholders' interests entails the realization that stakeholders will support collective action and the company's position therein only if complementarities are established that help stakeholders achieve the desired state on their own terms. Importantly, meeting stakeholders' interests is not a passive response strategy like acquiescence to external pressures (cf. Oliver, 1991; Pache \& Santos, 2010). It pertains to a 
more sophisticated positioning in the local field that recognizes and fosters rather than disturbs stakeholders' positions and identities, thereby avoiding antagonism. If successful in mobilizing action, the company's participation is disruptive, but its success likely hinges on promoting a sense of continuity (see also Ansari, Garud, \& Kumaraswamy, 2016). To mobilize collective action by aligning with external stakeholders, internal activists may thus frame the company's responsibilities in terms of stakeholders' interests. Such an understanding likely only arises, however, if stakeholders skillfully leverage their capacities and dependencies in their interactions with internal activists.

\section{Internal Alignment}

Internal alignment pertains to constructing or changing a framing so that it fits the understandings of other members in the organization. In the case at hand, internal alignment was used to fine-tune the emerging framing in an attempt to appeal to and mobilize company managers. I found that the internal activists strengthened internal alignment through two frame shifts: from most pressing issues to issues with greatest potential impact; and from remedial responsibility to the narrower conception of shared responsibility. Two processes constituted these shifts: recognizing managers' interests and confronting impracticability.

First, recognizing managers' interests entails understanding managers' objectives and decision-making principles. In the case studied here, the internal activists reframed the proposed course of action in terms of maximizing impact and thereby generated resonance with managers through centrality (Benford \& Snow, 2000); that is, by connecting to dominant "returns on investment" frame which was salient in managers' decision making. The new framing accordingly suggested that addressing the societal problem was indeed the company's business. While invoking the business case may suggest an instrumental approach to corporate responsibility (e.g., Orlitzky, Schmidt, \& Rynes, 2003), delimiting proposed 
action in these terms in fact expands what activities count as doing business. In this way, internal activists may use the business case for corporate responsibility as the mythological Trojan Horse to gain access to but eventually transform business decision making. To be able to understand and work with managers' interests, however, internal activists must have privileged access to and participate in organizational politics—while avoiding co-optation.

Second, confronting impracticability entails understanding that others do not understand the practical implications of the advocated solution and require stronger guidance as to suggested courses of action. In the case studied here, corporate managers were interested in developing a recipe for market transformation and subsidiary managers were seeking guidance as to how to put the proposed new way of doing business into practice. In response, the internal activists attempted to consolidate the company's responsibilities in a way that maintained external stakeholders' support for collective action while offering a stronger definition of the company's responsibilities that could guide the adoption of new ways of doing business. While this constitutive process led to the most sophisticated framing, it hinges on the condition that managers consider taking action. Accordingly, internal activists confront impracticability only if they have already achieved a high degree of internal alignment. As a result, multiple iterations of external alignment and recognizing managers' interests may be required before impracticability is confronted. The dashed arrow (a) in Figure 1 indicates this potential iterative step.

While the consolidation of the framing in response to confronting impracticability may strengthen internal alignment, the findings suggest that internal activists' talk — even when strongly aligned - does not immediately instigate action. Indeed, the internal activists' talk created a stronger demand for their talk, but it remained difficult for managers to put the conveyed understanding into practice. In the third phase of the Blueprint, the internal activists offered concrete guidance to managers by outline immediate courses of 
action for their specific subsidiary, effectively performing "contextualization work" (Gond \& Boxenbaum, 2013). However, to enable managers to independently define concrete courses of action in accordance with the shared responsibility understanding, they eventually attempted to prompt interpretive shifts through prolonged engagement and extensive training. The findings hence suggest that frame alignment may form a foundation for transforming action, but that talk must be complemented by initiatives that translate a shared but abstract understanding into practical reasoning.

Overall, the presented model proposes that external alignment precedes internal alignment. In the case at hand, external alignment indeed dominated the development of the framing before internal alignment became more salient. This sequencing may, however, be idiosyncratic to the case: as part of the external alignment, the internal activists in Novo Nordisk were challenged to understand the transformative ways of doing business that the subsidiaries in Bangladesh and Indonesia were already enacting and which management considered successful. This idiosyncrasy of the case explains the internal activists' focus on external alignment before they embarked on strengthening internal alignment. More generally, frame alignment likely entails multiple iterations of internal and external alignment: since internal alignment entails the more precise definition of a company's responsibilities and may transform business practice, it likely affects the local environments in which the company operates. As a result, it may then prompt re-negotiation with stakeholders, which in turn may catalyze further internal adjustments. The dashed arrow (b) in Figure 1 indicates such likely iterations. Accordingly, the processes that constitute internal and external alignment are interdependent, and likely not exhaustive, multidirectional steps in an iterative search for a compelling framing of a company's responsibilities. 


\section{Conclusion}

In this article, I aimed to advance our understanding of intra-organizational pressures for transformation toward more responsible business practices. To this end, the article explored the role of internal activists — protagonists of corporate responsibility — and asked how they develop framings of their company's responsibilities that promote new understandings of the company's responsibilities and thereby transform their company from the inside out. The findings show that internal activists increased frame alignment with both external stakeholders and internal managers. Over time, they developed a "shared responsibility" framing that promoted an understanding of the company's responsibility as relatively narrowly defined contribution to collective action. Theorizing the findings, the article presented a model of the frame alignment process that explicates the constitutive processes which enabled the internal activists to produce appealing and inspiring talk. In conclusion, this article makes several contributions to the literature on CSR communication.

First, this article contributes to our understanding of how CSR communication may bring about organizational transformation by drawing attention to intra-organizational dynamics. Previous studies have suggested that companies may talk themselves into commitment and action (Christensen et al., 2013; Haack et al., 2012). For instance, these studies highlight that CSR communication may involve elements of autocommunication: that is, external communication not only addresses external stakeholders, but also entails elements of self-talk that may_in theory_constitute changes in business practices (Christensen et al., 2013; Schoeneborn \& Vásquez, 2017). By opening the black box of intra-organizational dynamics, this article offers an empirically-grounded understanding of the constitutive processes that fueled internal activists' meaning-making and enabled them to construct a strongly aligned framing of their company's responsibilities. It shows that such framing efforts may extend well beyond selling social issues to top management (cf. Alt \& Craig, 
2016; Wickert \& De Bakker, 2016), and proposes that whether CSR communication brings about action hinges on the meaningful re-framing of corporate responsibility as the company's business.

Second, this article offers an explanation of how internal activists may use CSR communication to reconcile the interests of external stakeholders and internal managers. While previous studies have emphasized "communication to audiences from companies rather than with them" (Crane \& Glozer, 2016, p. 1230), this study has connected communication with external audiences to communication processes inside companies. It thereby suggests a re-conceptualization of CSR communication authored by internal activists as a boundary process (Weber \& Waeger, 2017) and highlights the role of internal activists as boundary-spanners. Boundary spanning refers to actors mediating across organizational well as intra-organizational boundaries (Leifer \& Delbecz, 1978; Tushman \& Scanlan, 1981; Weber \& Waeger, 2017; Williams, 2002). The internal activists studied here mediated between the understandings of external stakeholders and internal managers, thereby generating new understandings that repaired any conflictual mismatches. Because it may generate new shared understandings of a company's responsibilities, such mediating work may hold great potential for instigating organizational transformation and may generate innovative solutions to pressing societal problems.

Third, this article suggests that internal activists constitute a distinct type of change agent. This study shows that, like corporate intrapreneurs (Hemmingway 2005; Alt \& Craig 2016), internal activists may transform organizations from the inside out and from the bottom up. The process model developed here, however, highlights the importance of external alignment for how the internal activists developed their understanding as engaging with external stakeholders prompted critical reflection. In contrast, the process of internal alignment merely entailed fine-tuning the framing in an attempt to generate fit with dominant 
corporate ways of thinking. Indeed, inside a company, it is likely that any space for political discussion is quickly co-opted and reduced (Costas \& Kärreman, 2013). Scully and Segal (2002) capture this idea by proposing the notion of "passion with an umbrella": Organizational members may passionately engage in change initiatives that are important to them yet find their passion curtailed by the umbrella of management. Hence, the purpose of their activism may dilute when internal activists become absorbed into the corporate machinery (Wright \& Nyberg, 2017). In contrast to corporate intrapreneurs, internal activists must safeguard against co-optation and dilution of their agenda, and their boundary-spanning position may hence constitute a defining characteristic.

The case study of internal activists' framing efforts in Novo Nordisk presented in this article qualifies as a remarkably successful case, and the study of this exceptional case offered unique opportunities for advancing our understanding of intra-organizational dynamics in the context of CSR communication. At the same time, the idiosyncrasies of the case indicate a number of boundary conditions for the offered explanations. First, the company studied here is well-known as a frontrunner in corporate responsibility. Other companies may require strong external pressure to catalyze responsibilization and attract or enable the emergence of internal activists. Second, Novo Nordisk's top management had already espoused commitment to an integrated approach to corporate responsibility and to the Triple Bottom Line. As a result, corporate responsibility played a role in internal politics and stakeholder engagement processes. If a company has not already established an internal corporate responsibility discourse, internal activists likely face stronger resistance to their efforts and may therefore find themselves be pre-occupied by securing their own position and resources internally. In this scenario, they thus likely lack the organizational mandate and resources to engage with external stakeholders and hence forego the opportunity to generate a more sophisticated understanding of the company's responsibilities. Companies that have not 
yet established a corporate responsibility discourse internally likely still exhibit some form of stakeholder engagement, but any engagement will aim to inform and convince stakeholders of the company's message and may involve overwhelming them "like a battalion of tanks" (Helin, Jensen, \& Sandström, 2013).

For the emerging stream of research on the intra-organizational dynamics in the context of CSR and in particular the role of internal activists, the article suggests fruitful directions. While previous research has pointed out internal barriers to the implementation of sustainable business models (Olsen \& Boxenbaum, 2009), future research may focus on the organizational conditions under which internal activists thrive. The case study presented here indicates that organizational members may acquire familiarity with the internal politics of their organization and develop skills which then enable them to navigate and promote responsibility internally. One way to approach intra-organizational dynamics is hence to study how internal activists develop their framing practice and the implied social skills that enable them to promote change (Fligstein, 1997; Fligstein \& McAdam, 2012). What is more, this article suggests that the potential of internal activists to transform their companies stems from their unique boundary-spanning position from which they may mediate external stakeholder engagement and internal politics. However, in this position, internal activists may also face the challenge of overcoming marginalization and gaining access to executive management. How internal activists work with intra-organizational politics and the organizational conditions under which they thrive are exciting issues for future research.

\section{Acknowledgements}

I thank the Blueprint team at Novo Nordisk for sharing their journey with me. Along the way, I have benefited from discussions with many colleagues, especially Jasper Hotho, Dan Kärreman, Peer Hull Kristensen, and Luda Svystunova. I thank three anonymous reviewers, 
whose critical comments have helped and motivated me to develop this article, and Andrew Crane for his generous editorial guidance.

\section{References}

Aguinis, H., \& Glavas, A. (2012). What we know and don't know about Corporate Social Responsibility: A review and research agenda. Journal of Management, 38, 932-968.

Alt, E., \& Craig, J. B. (2016). Selling issues with solutions: Igniting social intrapreneurship in for-profit organizations. Journal of Management Studies, 53, 794-820.

Alvesson, M., \& Kärreman, D. (2011). Decolonializing discourse: Critical reflections on organizational discourse analysis. Human Relations, 64, 1121-1146.

Ansari, S., Garud, R., \& Kumaraswamy, A. (2016). The disruptor's dilemma: Tivo and the U.S. television ecosystem. Strategic Management Journal, 37, 1829-1853.

Benford, R. D., \& Snow, D. A. (2000). Framing processes and social movements: An overview and assessment. Annual Review of Sociology, 26, 611-639.

Boxenbaum, E., \& Jonsson, S. (2008). Isomorphism, diffusion and decoupling. In R. Greenwood, C. Oliver, K. Sahlin, \& R. Suddaby (Eds.), The SAGE Handbook of Organizational Institutionalism (pp. 78-98). London: Sage.

Bromley, P., \& Powell, W. W. (2012). From smoke and mirrors to walking the talk:

Decoupling in the contemporary world. The Academy of Management Annals, 6, 483530.

Brummans, B. H. J. M., Cooren, F., Robichaud, D., \& Taylor, J. R. (2014). Approaches in research on the communicative constitution of organizations. In L. L. Putnam \& D. Mumby (Eds.), Sage Handbook of Organizational Communication (pp. 173-194). Thousand Oaks, CA: Sage.

Charmaz, K. (2006). Constructing Grounded Theory: A Practical Guide through Qualitative Analysis. London: Sage.

Christensen, L. T., Morsing, M., \& Thyssen, O. (2013). CSR as aspirational talk. Organization, 20, 372-393.

Christiansen, L. J. H. (2013). Brewing Organizational Responses to Institutional Logics. Doctoral dissertation. Copenhagen Business School. Retrieved from http://openarchive.cbs.dk/handle/10398/8749

Cooren, F., Kuhn, T. R., Cornelissen, J. P., \& Clark, T. (2011). Communication, organizing and organization: an overview and introduction to the special issue. Organization Studies, 32, 1149-1170.

Corbin, J. M., \& Strauss, A. (2008). Basics of Qualitative Research (3rd ed.). Thousand Oaks, CA: Sage.

Cornelissen, J. P., Durand, R., Fiss, P. C., Lammers, J. C., \& Vaara, E. (2015). Putting communication front and center in institutional theory and analysis. Academy of Management Review, 40, 10-27. 
Costas, J., \& Kärreman, D. (2013). Conscience as control - managing employees through CSR. Organization, 20, 394-415.

Crane, A., \& Glozer, S. (2016). Researching Corporate Social Responsibility communication: Themes, opportunities and challenges. Journal of Management Studies, 53, 1223-1252.

Dewulf, A., Gray, B., Putnam, L., Lewicki, R., Aarts, N., Bouwen, R., \& van Woerkum, C. (2009). Disentangling approaches to framing in conflict and negotiation research: A meta-paradigmatic perspective. Human Relations, 62, 155-193.

Fligstein, N. (1997). Social skill and institutional theory. American Behavioral Scientist, 40, $397-405$.

Fligstein, N. (2001). Social skill and the theory of fields. Sociological Theory, 19, 105-125.

Fligstein, N., \& McAdam, D. (2012). A Theory of Fields. Oxford: Oxford University Press.

Gond, J. P., \& Boxenbaum, E. (2013). The glocalization of responsible investment: Contextualization work in France and Québec. Journal of Business Ethics, 115, 707721.

Granqvist, N., \& Laurila, J. (2011). Rage against self-replicating machines: Framing science and fiction in the US nanotechnology field. Organization Studies, 32, 253-280.

Gray, B., Purdy, J. M., \& Ansari, S. (2015). From interactions to institutions: Microprocesses of framing and mechanisms for the structuring of institutional fields. Academy of Management Review, 40, 115-143.

Haack, P., Schoeneborn, D., \& Wickert, C. (2012). Talking the talk, moral entrapment, creeping commitment? Exploring narrative dynamics in corporate responsibility standardization. Organization Studies, 33, 815-845.

Hamilton, A. L., \& Gioia, D. (2009). Fostering sustainability-focused organizational identities. In L. M. Roberts \& J. E. Dutton (Eds.), Exploring Positive Identities and Organizations: Building a Theoretical and Research Foundation (pp. 427-451). New York, NY: Psychology Press.

Helin, S., Jensen, T., \& Sandström, J. (2013). "Like a battalion of tanks": A critical analysis of stakeholder management. Scandinavian Journal of Management, 29, 209-218.

Hoffman, A. J. (1999). Institutional evolution and change: Environmentalism and the US chemical industry. Academy of Management Journal, 42, 351-371.

Joutsenvirta, M., \& Vaara, E. (2015). Legitimacy struggles and political Corporate Social Responsibility in international settings: A comparative discursive analysis of a contested investment in Latin America. Organization Studies, 36, 741-777.

Kaplan, S. (2008). Framing contests: Strategy making under uncertainty. Organization Science, 19, 729-752.

Khaire, M., \& Wadhwani, R. D. (2010). Changing landscapes: The construction of meaning and value in a new market category--Modern Indian Art. Academy of Management Journal, 53, 1281-1304.

Koschmann, M. A., Kuhn, T. R., \& Pfarrer, M. D. (2012). A communicative framework of value in cross-sector partnerships. Academy of Management Review, 37, 332-354.

Langley, A. (1999). Strategies for theorizing from process data. Academy of Management 
Review, 24, 691-710.

Lefsrud, L. M., \& Meyer, R. E. (2012). Science or science fiction? Professionals' discursive construction of climate change. Organization Studies, 33, 1477-1506.

Leifer, R., \& Delbecz, A. (1978). Organizational/environmental interchange: A model of boundary spanning activity. Academy of Management Review, 3, 40-50.

Lounsbury, M., Ventresca, M. J., \& Hirsch, P. (2003). Social movements, field frames and industry emergence: a cultural-political perspective on US recycling. Socio-Economic Review, 1, 71-104.

Matten, D., \& Crane, A. (2005). Corporate citizenship: Toward an extended theoretical conceptualization. Academy of Management Review, 30, 166-179.

McDonnell, M.-H., King, B., \& Soule, S. (2015). A dynamic process model of contentious politics: Activist targeting and corporate receptivity to social challenges. American Sociological Review, 80, 654-678.

Meyer, J. W., \& Rowan, B. (1977). Institutionalized organizations: Formal structure as myth and ceremony. American Journal of Sociology, 83, 340.

Meyer, R. E., \& Höllerer, M. A. (2014). Does institutional theory need redirecting? Journal of Management Studies, 51, 1221-1233.

Mohr, L. B. (1982). Approaches to explanation: Variance theory and process theory. In Explaining Organizational Behavior (pp. 35-71). San Francisco, CA: Jossey Bass.

Oliver, C. (1991). Strategic responses to institutional processes. Academy of Management Review, 16, 145-179.

Olsen, M., \& Boxenbaum, E. (2009). Bottom-of-the-Pyramid: Organizational barriers to implementation. California Management Review, 51, 100-125.

Orlitzky, M., Schmidt, F. L., \& Rynes, S. L. (2003). Corporate social and financial performance: A meta-analysis. Organization Studies, 24, 403-441.

Pache, A., \& Santos, F. (2010). When worlds collide: The internal dynamics of organizational responses to conflicting institutional demands. Academy of Management Review, 35, 455-476.

Porter, M., Hills, G., Pfitzer, M., Patscheke, S., \& Hawkins, E. (2011). Measuring shared value: How to unlock value by linking social and business results. In Shared Value Summit Proceedings (pp. 1-24).

Reinecke, J., \& Ansari, S. (2016). Taming wicked problems: The role of framing in the construction of Corporate Social Responsibility. Journal of Management Studies, 53, 299-329.

Scherer, A. G., Rasche, A., Palazzo, G., \& Spicer, A. (2016). Managing for Political Corporate Social Responsibility - New challenges and directions for PCSR 2.0. Journal of Management Studies, 53, 273-298.

Schoeneborn, D., \& Vásquez, C. (2017). Communicative Constitution of Organizations. In C. R. Craig R. Scott, L. Lewis, J. R. Barker, J. Keyton, T. Kuhn, \& P. K. Turner (Eds.), International encyclopedia of organizational communication (pp. 367-386). Hoboken, NJ: Wiley. 
Scully, M., \& Segal, A. (2002). Passion with an Umbrella: Grassroots activists in the workplace. In M. Lounsbury \& M. J. Ventresca (Eds.), Research in the Sociology of Organizations: Social Structure and Organizations Revisited (Vol. 19, pp. 125-168). Emerald Group Publishing.

Snow, D. A., Rochford, E. B., Worden, S. K., \& Benford, R. D. (1986). Frame alignment processes, micromobilization, and movement participation. American Sociological Review, 51, 464-481.

Strand, R., \& Freeman, R. E. (2015). Scandinavian cooperative advantage: The theory and practice of stakeholder engagement in Scandinavia. Journal of Business Ethics, 127, 6585 .

Strand, R., Freeman, R. E., \& Hockerts, K. (2015). Corporate Social Responsibility and sustainability in Scandinavia: An overview. Journal of Business Ethics, 127, 1-15.

Tushman, M. L., \& Scanlan, T. J. (1981). Boundary spanning individuals: Their role in information transfer and their antecedents. Academy of Management Journal, 24, 289305.

Weber, K., Heinze, K. L., \& DeSoucey, M. (2008). Forage for thought: Mobilizing codes in the movement for grass-fed meat and dairy products. Administrative Science Quarterly, $53,529-567$.

Weber, K., \& Waeger, D. (2017). Organizations as polities: An open systems perspective. Academy of Management Annals, 11, 886-918.

Werner, M. D., \& Cornelissen, J. P. (2014). Framing the change: Switching and blending frames and their role in instigating institutional change. Organization Studies, 35, 14491472 .

Wickert, C., \& De Bakker, F. G. A. (2016). Pitching for social change: towards a relational approach to selling and buying social issues. Academy of Management Discoveries, Advance online publication.

Williams, P. (2002). The competent boundary spanner. Public Administration, 80, 103-125.

World Health Organization. (2014). Global Status Report On Noncommunicable Diseases 2014. Retrieved from http://apps.who.int/iris/bitstream/10665/148114/1/9789241564854_eng.pdf?ua=1

World Health Organization. (2017). Noncommunicable diseases progress monitor 2017. Retrieved from http://apps.who.int/iris/bitstream/10665/258940/1/9789241513029eng.pdf?ua $=1$

Wright, C., \& Nyberg, D. (2017). An inconvenient truth: How organizations translate climate change into business as usual. Academy of Management Journal, 60, 1633-1661. 
Tables and Figures

Table 1: Timeline of the Blueprint for Change Reports

\begin{tabular}{|c|c|c|c|}
\hline Issued & Title & Code & \# of pages \\
\hline 2011 & Changing diabetes in China & $\mathrm{CN}$ & 16 \\
\hline 2012 & $\begin{array}{l}\text { Creating shared value through socially responsible initiatives in } \\
\text { the United States }\end{array}$ & US & 28 \\
\hline 2012 & $\begin{array}{l}\text { Changing diabetes in Bangladesh through sustainable } \\
\text { partnerships }\end{array}$ & $\mathrm{BD}$ & 24 \\
\hline 2013 & $\begin{array}{l}\text { Where economics and health meet: changing diabetes in } \\
\text { Indonesia }\end{array}$ & ID & 28 \\
\hline 2014 & Developing partnerships to change diabetes in India & IN & 20 \\
\hline 2014 & Innovating diabetes care in Turkey & TU & 24 \\
\hline 2015 & Investing in diabetes care in Russia & RU & 24 \\
\hline 2016 & Partnering to innovate diabetes care in Algeria & $\mathrm{AL}$ & 28 \\
\hline 2017 & Meeting the challenge of diabetes in a super-aged society (Japan) & $\mathrm{JP}$ & 24 \\
\hline
\end{tabular}


Table 2: Data Structure and Illustrative Quotes

Previous framing
New framing
Constitutive process

\section{External alignment}

1a: Complex and multiple root causes

"Urbanisation, high calorie diets and physical inactivity are all lifestyle related factors known to cause diabetes" (CN, p. 2) 1b: $\quad$ Stakeholders in need of assistance

"The Triple Bottom Line is grounded in the needs of patients and society." (US, p. 4)

\section{Barriers to achieving desired Understanding desired state state}

"Complex issues involving awareness, accessibility, affordability and availability have prevented millions of people who live with diabetes from receiving highquality care" (BD, p. 2)

\section{Stakeholders as partners}

"Novo Nordisk takes a conscious partnership approach that identifies patient needs and ensures sustainable business models throughout the value chain. It means that each partner should gain from the collaboration." (ID, p. 23)

"In the context of developing countries and emerging markets, we need to understand: What are the ingredients for genuine market transformation?" (Blueprint team member, Aug 12)

\section{Recognizing stakeholders capacities}

"[The subsidiary] uses [stakeholders] very differently in different occasions and in different activities. In some activities, they need their support and knowledge, so they use them in some ways. Sometimes, they use one stakeholder to reach another stakeholder." (Blueprint team member, Nov 12)

\section{Remedial responsibility}

Acknowledging stakeholders' interests

"We are investing ahead of the curve, making substantial internal improvements that enable us to partner with others on initiatives aimed at breaking down barriers to better diabetes care."

(ID, p. 7)
"The perception of stakeholders can be biased, so we need to show value as good beginning for Manager of ID subsidiary, Sep 12) collaboration" (General and pursue business solutions that generate value to business, patients, and society." (US, p. 1) 


\section{Internal alignment}

2a: $\quad$ Most pressing issues

"We collaborate with our partners on activities and programmes that address issues most acutely in need of attention. These activities become drivers of how we create value." (ID, p. 7)

2b: Remedial responsibility (see above)

\section{Issues with greatest potential Acknowledging managers' interests}

"Together with partners, we work to address this by focusing on areas where we can have the biggest positive impact, and in the process create shared value for society and our company." (TU, p. 2)

\section{Shared responsibility}

We collaborate directly with partners to address complementary needs, such as patient education. For needs that are beyond our core competence, we may facilitate the bringing together of stakeholders with different competencies."

(TU, p. 8)
"The way that decisions navigate a lot is through top management looking at where do I see growth potential. And where can I do that with the least effort. And where can I invest to realize the potential." (Blueprint team member,

May 2015)

\section{Confronting impracticability}

"To convince local GMs, they need to see solutions invented in their own backyard! ... People who are leading see that it matters, but not how to do it." (Blueprint team member, May 2015) 


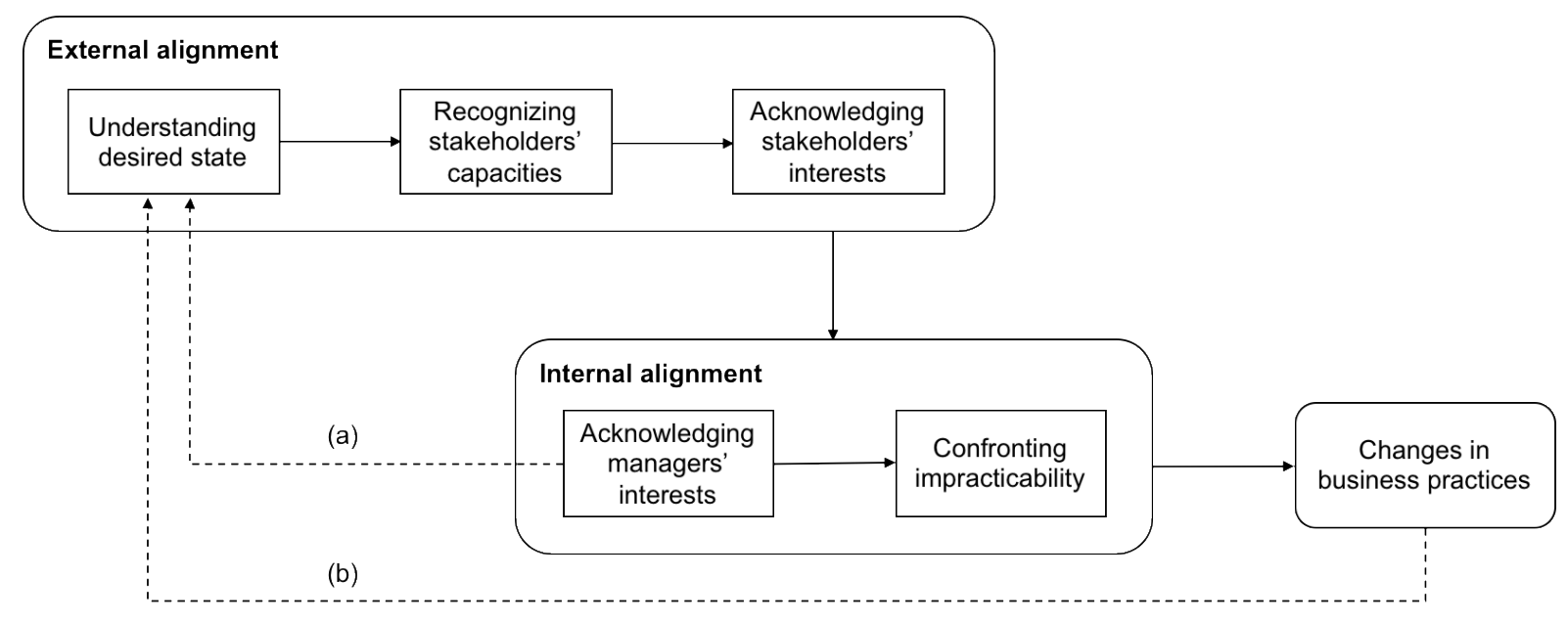

Figure 1: Model of Frame Alignment for Corporate Responsibility 